\title{
Management Principles Associated With IT Project Success
}

John Nicholas, Loyola University Chicago, USA

Gezinus Hidding, Loyola University Chicago, USA

\begin{abstract}
Success in information technology (IT) projects remains elusive, even after decades of efforts to improve it. Most of these efforts have focused on variations of the traditional project management paradigm as promulgated by PMBOK. We suspected that a potential cause of high IT project failure is with the paradigm, which focuses on the project itself and on meeting time and cost targets. A new paradigm called Value-Driven Change Leadership (VDCL) originated from discussions of a panel of project management experts. This paper describes the principles of that paradigm. It also reports the results from a survey of four project managers on the association between project success and management principles from VDCL and PMBOK.
\end{abstract}

Keywords: I.T. Project Management, Project success, Project failure, PMBOK, VDCL, Value, Leadership, Architecture

\section{INTRODUCTION}

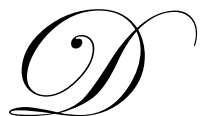

o managers of successful projects emphasize management principles or practices that those of unsuccessful projects do not? This paper addresses that question and considers which principles and practices differentiate successful projects from unsuccessful ones. We review the literature on project success and factors contributing to success or failure. We then describe a new paradigm or set of principles identified by a panel of experienced Information Technology (IT) project managers. The principles in this paradigm, called Value-Driven Change Leadership (VDCL), differ from those of traditional paradigms, such as represented by the Project Management Institute's (PMI) (2008) Project Management Body of Knowledge (PMBOK). A possible cause of IT project failure is the sole focus on the traditional project management paradigm and neglect of others, such as VDCL. To investigate the association between successful projects and the principles from VDCL and PMBOK, we interviewed four project managers who had each recently completed two projects one successful and the other unsuccessful. We asked them how much they applied principles from VDCL and PMBOK in managing their projects and compared the results to see which principles were emphasized more in the successful projects than in the unsuccessful projects.

\section{LITERATURE REVIEW}

There are two schools of thought about what constitutes project success: efficiency and effectiveness. The efficiency school defines success as the project's management process having been successful in terms of delivering the project on time and on budget. This definition focuses on the project's process, activities and resources (see Pinto and Slevin, 1988a). In contrast, the effectiveness school defines success as the project's outcomes having been successful in terms of, e.g., enhancing productivity, sales, or profits (see, e.g., De Wit, 1988). This school focuses on the project's end results and stakeholders. Cooke-Davies (2002) formally distinguishes the two definitions, calling the former project management success and the latter project success. Some authors argue in favor of using both ways (Atkinson, 1999) or that different measures apply depending on different phases of the project life cycle (Pinto and Slevin, 1988b). 


\section{Research on IT Project Success and Failure}

Project success and failure has long interested management researchers. A 1968 NATO-sponsored conference addressed "software failure" and "software crisis" and noted that large systems "are encountering great difficulties" (Nauer and Randell, 1968). At the conference, J. Licklider reported that of "two or three dozen complex electronic systems for [military] command, control and/or intelligence operations," most were never completed and none was completed on time or within budget (Randell, 1979). Hank Lucas (1975) did a PhD dissertation on "Why Information Systems Fail." Jenkins et al. (1984) found that IS development projects had a median cost overrun of $33.5 \%$, median person-day overrun of $36 \%$, and average schedule overrun of $22 \%$; it also found that nearly twice as many software projects were completed late $(32.9 \%)$ and on time $(17.5 \%)$. Phan and Nunamaker (1988) reported that only $16.5 \%$ of software projects were completed on budget; $41 \%$ were over budget by an average of $33 \%$.

Many studies, e.g., Glass (1999), have chronicled the failure of particular projects, including those by the Standish Group that show high failure rates among IT projects over the past 15 years (www.standishgroup.com). Standish Group (2006) reported that $46 \%$ of projects were completed late or over budget and/or did not fulfill functional requirements, $19 \%$ were canceled before completion, and only $35 \%$ were completed on time, on budget, and met requirements. (Some have argued that these results are biased (e.g., Jorgensen and Molokken, 2006).

\section{Research on Factors Associated with Project Success and Failure}

Researchers have also been interested in the factors that appear associated with project success and failure. Factors associated with failure include, e.g., lack of agreement on project goals or use of appropriate development methodology, project uniqueness, volatility of requirements, and inadequate technology or infrastructure (see, e.g., Ewusi-Mensah, 2003, or Tiwana and Keil, 2004). Size seems to matter - the larger the project, the greater the probability of failure (see, e.g., Sauer et al., 2007, and Jenkins et al., 1984). Factors associated with project success (and whose absence is associated with failure) include, e.g., clearly set success criteria, commitment of the project team to project goals, and adequate project team capability (see Baker et al., 1988).

Many studies, e.g., Cooke-Davies (2002), O’Connor and Reinborough (1992), Pinto and Slevin (1988b), and Yourdon (2004), have concluded that, ceteris paribus, project success or failure depends on the way the project is managed; i.e., the extent to which project management, e.g., sets clearly defined project goals, wins executive support, exercises leadership, manages project scope, plans and organizes the project, communicates with stakeholders, involves users, manages risks, gives timely progress feedback, and adapts to unexpected events.

\section{Normative Models of Project Management}

A huge literature is devoted to prescribing how projects should be managed, although little of it is empirically tested. Proliferation of prescriptions derives from multiple perspectives of project management that include (Kolltveit et al., 1997): task (management of tasks and resources), leadership (team effectiveness, leadership style), system (e.g., technology base or infrastructure), stakeholder (e.g., agreement on project goals), transaction costs (e.g., goal commitment of the project team), and business-by-project (e.g., focus on project results). Each perspective suggests a set of principles about what constitutes the most effective way to manage projects, many of which have been incorporated into traditional project management thinking. For example, PMBOK's nine knowledge areas mostly represent the "task perspective;" PMBOK primarily addresses the management of activities and resources to achieve on-time and on-budget completion of projects. The principles of PRINCE2 (Office of Government Service, 2005) also emphasize this perspective and overlap with PMBOK.

\section{VALUE-DRIVEN CHANGE LEADERSHIP}

Management principles derived from PMBOK and other normative models have been promoted for decades in books, training materials, college curricula, and professional certifications (e.g., PMP), yet project performance in many industries, especially IT, remains generally poor and project failures remain high. Thus, we suspected something might be missing from these models. To find out and possibly discover other principles about 
the way projects should be managed, we convened a yearlong series of meetings with a panel of IT project managers.

\section{Expert Panel}

The panel consisted of 17 men and 3 women with 10-40 (average 20) years of experience in managing IT projects in a variety of industries. We asked the panel to consider the question, "What management principles and practices, other than those espoused in PMBOK, should managers follow to increase the likelihood of project success?" To delimit their thinking, they focused on projects one-month to one-year duration and for 3 to 50 project personnel. Over the period of one year, they met many times to define, discuss, and rank the management principles they felt contributed the most to project success. In the end, they reached consensus on a set of principles we call Value-Driven Change Leadership (VDCL). Though the principles are targeted to managing medium-sized IT projects, we believe many of them might also apply to the management of larger or non-IT projects, but that is presently beyond the scope of our research.

\section{Fundamental Principles}

VDCL consists of 13 principles organized into three themes: "value/outcome over budget/ schedule," "business solutions over architecture framework," and "human change over repeated activities." We adopted this "x over y" formulation to emphasize new ways of thinking while not necessarily discarding existing ways.

\section{Theme 1: Value/Outcome over Budget/Schedule}

The traditional perspective on project management says that a project completed on schedule and within budget is a success; it also suggests that a project completed behind schedule and over budget is unsuccessful. A contrasting perspective says to ignore the budget and schedule and instead look at outcomes. Simply, a project whose long-term benefits exceed the costs is a success and one whose costs exceed long-term benefits is a failure. The expert panel adopted the latter perspective. As one member said, "Firms invest in IT to create value, not software." The panel felt that the value provided by a project's end result is what matters most, more so than the cost and schedule of developing that result. This perspective - that delivering benefits and value to the customer - is the primary aim of project management-is widely held, e.g., Andersen et al. (1984), Cooke-Davies (2002), Lipovetsky et al. (1997), Male et al. (1997), Shenhar and Dvir (2007), Tedesco (2006), and Ward and Daniel (2006). The theme "value/outcome over budget/schedule" says that project managers must seek to balance the project cost and schedule with project benefits, both tangible (e.g., financial return) and intangible (e.g., company image) (see Murphy, 2002, and Phillips et al., 2002). The theme has five principles:

Principle 1 (or V1) is "tracking business value-added benefits over tracking conformity to plans and schedules." Successful projects focus on the business benefits of the end results, not only on project performance in terms of cost and schedule.

Principle 2 (V2) is "managing the business case over abandoning the business case." IT projects are typically approved based on a business case, but then are managed to a budget and a schedule, not to the business case; in effect, the business case is abandoned. The panel felt the business case should guide the entire projectbefore kick-off (to clarify success metrics and evaluate project alternatives), during execution (to assess change requests and trade-off decisions), and after closeout (to assess actual business results).

Principle 3 (V3) is "all stakeholders and team members agreeing on the project's purpose and value-added measures over some stakeholders and members agreeing." The panel felt that everyone working in the project (team members, subcontractors, etc.) should understand and agree on the same set of value-added outcomes and success metrics.

Principle 4 (V4) is "all team members having a stake in the success or failure of the project over not having it." Having a stake in the project implies the team has a personal commitment and the motivation to make the project succeed. 
Principle 5 (V5) is "quantifying the financial impact of risks over simply listing the risks". The panel felt that risk management methods that focus on qualitative risk assessment are insufficient; the methods should include assessment of the financial impact of combinations of risks as well.

\section{Theme 2: Business Solutions over Architecture Framework}

The panel felt that too often IT projects, particularly medium-sized ones, disregard the explicit architecture of the end product. Architecture is defined as a representation or description of the structure of the end-result system, which includes: 1) modules of the system, their relative configuration, and the functions they perform; 2) interfaces (input/output/control) among the modules; and 3) syntax of the interfaces (specification of how modules will be accessed or invoked). The theme "business solutions over architecture framework" says that the system architecture should focus on fulfilling business needs. While project managers do not need to be architects, they do need to ensure that the architecture of the end product system is explicitly addressed by the project plan (Paulish, 2002). Said one panel member, "Ignoring architecture is rather like ignoring the core of a skyscraper. Skyscrapers are built not wall by wall; they are built floor by floor, around the core." This view is a systems approach to project management (Nicholas and Steyn, 2008). The theme has four principles:

Principle 1 (A1) is "attending to architecture over ignoring architecture". The panel felt that system architecture in many projects is either ignored or inadequately addressed. Rather than tailoring architecture to the desired end result, the default approach is to adopt the pre-existing architecture. Architecture should be a key aspect of the end product and, therefore, of the project plan.

Principle 2 (A2), an extension of A1, is "designing architecture to provide specific business solutions over choosing from among generic frameworks". The panel felt that often project managers view architecture as a matter of selecting from a limited set of pre-existing architecture frameworks, such as SOA, Zachman, or .NET. They argued that for each end product, the system architecture should be designed to specifically fulfill the product's business goals.

Principle 3 (A3) is "completing the end product in frequent small releases over in one big release". Each release should deliver incremental business benefits and address current priorities or risks. PMBOK does not address multiple end-product releases, but other project management approaches do, e.g., Agile Development (Cockburn, 2002) and SCRUM (Sutherland, 2004). The panel felt that for IT products, the first release should establish the architecture for subsequent releases.

Each kind of architecture has advantages, disadvantages, and associated risks; hence, Principle 4 (A4), which is "choosing the best end-product architecture from among several alternatives over choosing whatever is available or the easiest to adopt". In the early stages of project planning, different architectures should be developed and assessed.

\section{Theme 3: Human Change over Repeated Tasks}

Every IT project introduces something new in an organization and, thus, involves organizational change. The panel felt that since change is inherent to projects, project managers should address issues related to successful change such as learning, consensual agreement, change support, and treating people as individuals. This theme thus focuses on leadership and has four principles:

The first (L1) is "changing organizations over delivering products". The panel felt that in addition to delivering an end product, the project should prepare the organization to adopt the end product for effective use. Thus, the project should address, e.g., executive support, communication, training, ways to reduce resistance, and incentives (Conner, 1992).

Principle 2 (L2) is "improving activities over repeating activities". The failure of a succession of projects suggests a failure to learn from each project (Abdel-Hamid and Madnick, 1990). The panel argued that in every project, the manager must strive to learn from previous projects, contemporaneous projects, and the project itself. A 
role of the manager is to help the project team learn from the past and explore ideas for improvement.

Principle 3 (L3) is "developing human relations over interchanging resources". The panel argued that individual stakeholders inside and outside the project should be treated as "whole persons"-individuals with unique skills, experiences, interests, and influences on the project, not as interchangeable entities.

Principle 4 (L4) is "finding common ground over negotiating personal interests". Project work is best done on the basis of trust and agreement (Weisbord and Janoff, 2000). This principle advocates an "agree-to-agree" stance instead of negotiation to avert conflict or controversy; i.e., start by finding common ground upon which to agree and then work from there.

\section{RESEARCH QUESTION}

The question posed to the expert panel was "what other principles, besides those in PMBOK, should managers observe to improve the likelihood of project success?" The principles espoused in PMBOK emphasize adherence to project budgets, schedules, and requirements, which are, in effect, measures of the project management process. While the principles of VDCL do not deny the importance of the project management process, they are focused on project outcomes. Thus, we posed this simple research question: Which principles from VDCL and PMBOK are associated with project success?

\section{INTERVIEWS}

We address the research question by conducting structured interviews with project managers. Each interview focuses on information about a particular project, specifically the project itself, the project manager, the organization wherein it was conducted, and whether it had met its goals and provided the intended benefits. It also focuses on management practices - the extent to which the manager observed project management principles. Our expert panel reviewed all the statements to be used in the interviews for content validity of the constructs for the dependent and independent variables (Petter et al, 2007).

\section{Dependent Variable: Success}

The dependent variable is success, conceptualized in two ways. The first way is project outcomes, which we measure by the degree to which

- $\quad$ end product is used as intended

- $\quad$ project contributes to the organization's value-added (taking into account all costs and benefits)

- $\quad$ intangible benefits exceed tangible benefits

The other way is project management process, which we measure by comparing

- $\quad$ expected project duration to the actual project duration (i.e., schedule)

- $\quad$ expected project expenditures to the actual project expenditures (i.e., costs)

- $\quad$ expected project person hours to the actual project person-hours (labor resources)

\section{Independent Variables: Project Management Principles}

Our structured interviews include a series of statements - one for each of the 13 VDCL principles and nine PMBOK knowledge areas. Responses to these statements measure the amount of emphasis a manager placed on particular management principles while managing a given project; these are the "independent variables". The degree of emphasis is gauged using a 7-point ordinal scale to register a manager's agreement or disagreement with the statement. We pilot tested the statements on four other project managers to ensure that each statement was clearly understood and represented the VDCL principles and PMBOK knowledge areas as intended. 


\section{Independent Variables: Contextual Factors}

The interviews also address project success as potentially depending on "contextual factors"; i.e., aspects of the project itself, of the project manager, and of the organization and industry of the project. These factors include, e.g., the business functions impacted by the project, the person or role accountable for the success of the project, and the department(s) s to whom the project manager reports. They also include the project manager's age, gender, years of managing projects, and certifications (e.g., PMP) held, as well as aspects of the organization in or for which the project is performed, e.g., its age, revenues, the industry(ies) in which it operates, and whether it is for-profit or nonprofit.

\section{PROJECTS AND PROJECT MANAGERS IN THE SURVEY}

The first phase of our research (which is what this paper reports) focused on recently completed mediumsized IT-intensive projects within large organizations. We define "IT-intensive" as projects where a significant portion of the end product(s) consists of information technology. We contacted IT program managers and executives in several Chicago-area based organizations and asked them to identify project managers for our study.

We chose four project managers in nationally known organizations in the utilities, insurance, industrial products, and healthcare industries. Each of the managers had recently completed two projects - one widely viewed as being successful and the other widely viewed as unsuccessful. That is, we gathered data on four pairs of projects, each pair managed by the same project manager in the same organization, and each having one successful and one unsuccessful project. By comparing aspects of the successful project with the unsuccessful project in each pair, we hoped to reduce within-pair variability in outcomes due to organizational contextual factors, such as top management, culture, policies, and methodologies for project management and system development. Also, since the project manager is the same for both projects in a pair, we hoped to reduce within-pair variability due to the project manager factors, such as gender, age, project management experience, and education. We acknowledge that even some of these factors could change from project to project, even within the same organization; however, we expect such variability within the pairs to be less than variability between projects with different managers in different organizations.

Each project manager was sent a copy of the statements to review (the list of statements is included at the end of this paper) regarding two projects, followed by a personal interview with both authors. Among the four managers interviewed, one had 23 years of project management experience, two had 9 years, and the other had 4 years. One of the managers was PMP certified; the others were not. Three are female; one is male.

\section{RESULTS}

\section{Project Success}

We asked senior managers at the four organizations to introduce us to project managers who each had recently completed two projects - one "widely viewed" in the company a successful and the other widely viewed as unsuccessful - but we did not explain to them what we meant by "success".

Also, we did not directly ask the project managers which project was successful and which one was not. Rather, we derived which was which from the managers' responses to three statements in the interview: 1) the project's end-product has been used as intended; 2) the project was a success in terms of the organization's valueadded; 3) the project's intangible benefits (i.e., those that could not be quantified in financial terms) were much larger than the project's tangible benefits (i.e., those that were quantified in financial terms).

It turned out that in the three of the four project pairs, the managers associated project success with intangible benefits exceeding the tangible benefits. In three of the pairs for which complete data were available, the managers also associated project success with the project's contribution to organization's value-added. 


\section{Project Management Process}

Five of seven projects for which numerical data were available overran the schedule, although in two of the project pairs, the overruns for the successful projects were much smaller than for the unsuccessful ones ( $27 \%$ versus $75 \%$ and $4 \%$ versus 100\%). In a third pair, the overrun for the successful project was $60 \%$ and for the unsuccessful project, the overrun was indeterminable because the project was still underway. In another pair, the successful project finished on schedule, but the unsuccessful project was ahead of schedule.

Of the seven projects that provided budget data, five exceeded the budget. In one pair, the successful project had a greater budget overrun than the unsuccessful project (34\% versus $7 \%$ ). For another pair, the overrun was $18 \%$ for the successful project and $63 \%$ for the unsuccessful one. In a third pair, both projects finished somewhat below budget.

Only one project pair provided labor-hour figures for both the successful and the unsuccessful projects. Both projects overran the estimated labor-hours; for the successful project, the overrun was $19 \%$ for the unsuccessful project, it was $201 \%$.

In summary, in terms of the project management process, five of the projects were failures, even though managers had categorized three of them as "successful".

\section{Project Management Principles}

Among the PMBOK and VDCL project management principles investigated, we found several associated more with the successful projects than with the unsuccessful projects.

We identified two management principles that all four project managers had emphasized more in the successful project than in the unsuccessful ones: 1) managing expectations of all the stakeholders and 2) obtaining stakeholder agreement and team member understanding of the project's purpose and measures of value-added. The first principle is from PMBOK (communications management) and the second from VDCL (V3).

We identified another ten management principles that three of the four managers had emphasized more in successful projects than in unsuccessful projects. Five of the principles are associated with PMBOK:

- $\quad$ Manage the project's scope

- $\quad$ Manage the project's schedule and resources

- $\quad$ Initiate the project with a business case/charter

- $\quad$ Manage the project risk

- $\quad$ Maintain project sponsorship

The other five are from VDCL:

- $\quad$ Focus on achieving the goals of the business case (V2)

- $\quad$ Allow time in the project for reflection and learning (L2)

- Design and evaluate alternatives for the end-product's architecture and/or business functions early in the project (A4)

- $\quad$ Establish the architecture of the end-product as of the project's first release (A1)

- $\quad$ Account for the end-item's architecture in the project plan.

The remaining project management principles from VDCL and PMBOK showed no clear association with either successful or unsuccessful projects. 


\section{CONCLUSION}

The purpose of our research was to identify project management principles that contribute to project success. After an expert panel identified the VDCL set of principles, we wondered if emphasis on those principles, either alone or in combination with principles based on PMBOK, contributes to project success. By analyzing pairs of projects that were managed by the same project manager within the same organization, we hoped to control for differences in organizational context and project manager characteristics. Our sample of eight projects from four project managers is too small to provide statistically meaningful results; however they do lead to intriguing questions and hypotheses.

One question pertains to how organizations define success. As five of seven projects exceeded the estimated schedule and budget, they were failures according to the traditional project management criteria of adherence to budget and schedule. But in the minds of senior managers who selected these projects for us, three of them were "widely viewed as successful", and another project, which was completed ahead of schedule and under budget, was "widely viewed as unsuccessful". De facto, their view of "success" appears focused on project outcomes, and not on the project management process.

Does this mean for some projects and organizations that the project budget and schedule do not matter as much as the project outcomes? We suspect that for the kinds of projects we surveyed- "internal" IT projects in large organizations - the answer is yes. For "external" or contracted projects, however, targets for project completion date and cost are usually more clearly defined and of greater relative importance to success. Perhaps for projects such as these the PMBOK principles are more applicable to project success than for internal projects.

Our research showed associations between project success and 12 of the 22 principles we investigated (i.e., managers emphasized these principles more in the successful projects than in unsuccessful ones). Six of the principles are from PMBOK and six from VDCL. We cannot say that emphasis on the principles "caused" projects to be successful, although, in general, greater emphasis on certain practices in successful projects and lack of emphasis on the same principles in unsuccessful projects would suggests causality, especially since management practices (independent variables) temporally precede project outcomes (dependent variables); any association would flow from emphasis on principles to project outcomes, and not the reverse.

The survey found six of VDCL's 13 principles associated with successful projects. The principles represent all three of the VDCL themes-value-added, change leadership, and system architecture. It also found principles from six of PMBOK's nine knowledge areas associated with the successful projects. But this made us wonder: what about the other principles - three from PMBOK and five from VDCL — for which we did not see an association? Certainly after decades of the PMI promoting PMBOK, one would think there must be good reason for PMBOK having nine knowledge areas, not six. And our expert panel, after a year's work, came up with 13 VDCL principles, not six. Why didn't we see an association between all of the principles and the successful projects? Perhaps emphasis on the principles and project success depends on the kind of project or the organization doing the project.

We had suspected that the traditional PMBOK paradigm was in some way incomplete and that other principles might be necessary to increase the likelihood of project success. In general, in the successful projects we surveyed, managers showed greater emphasis on principles from both VDCL and PMBOK. This raises the question of whether project success involves principles from both PMBOK and VDCL, or perhaps that PMBOK and VDCL are in some way related.

\section{IMPLICATIONS FOR FURTHER RESEARCH}

The survey raises a number of interesting research questions that our small sample could not address. For one, is the association between principles from VDCL or PMBOK and project success statistically significant? Also, are the principles in VDCL and PMBOK independent or related; i.e., are the principles in one set correlated with those in the other? If the principles in the two sets are independent, are the principles in one set associated more with project success than those in the other; i.e., does one set of principles impact success more than the other? 
And if the principles in the two sets are independent, does emphasizing principals from both sets have a greater impact on project success than emphasizing principals from just one set? And finally, that age-old question, what is project success? This study suggests that success might depend on the kind of project and/or the organization for (or in) which the project is being done.

To begin to answer to these questions requires a survey of a large number of projects, project managers, and organizations. That survey is currently underway.

\section{AUTHOR INFORMATION}

John Nicholas, Professor in the School of Business Administration at Loyola University Chicago, is an active teacher and writer in project management and manufacturing management. He is the author of many academic and technical publications and several books including Project Management for Business, Engineering, and Technology (2008, with Herman Steyn) and Lean Production for Competitive Advantage (2010). Prior to Loyola he held such positions as engineering team leader and research analysts at Lockheed-Martin, Bank America, and Argonne National Laboratory. He has a BS in aerospace engineering and an MBA from the University of Illinois, Urbana, and a $\mathrm{PhD}$ in industrial engineering from Northwestern University.

Gezinus Hidding is an Associate Professor who joined the faculty of the School of Business Administration of Loyola University Chicago in 1996, after a 10-year career with Andersen Consulting (now Accenture). He has authored over 20 refereed publications. He has consulted with various organizations in topics of his teaching and research interests, including project management, systems development methods, and strategic use of IT. Dr. Hidding received his M.Sc. and Ph.D. in Information Systems from the Tepper School of Business of Carnegie Mellon University, and a B.Sc. and M.Sc. in Econometrics from the University of Groningen in the Netherlands.

\section{REFERENCES}

1. Abdel-Hamid, T.K.,S.E. Madnick, "The Elusive Silver Lining: How We Fail to Learn from Software Development Failures", Sloan Management Review, Fall 1990, pp. 39-48.

2. Andersen E.S., K.V. Grude, and T. Haug, Goal Directed Project Management: Effective Techniques and Strategies, Second Edition, Kogan Page, London, UK, 1984.

3. Atkinson, R. "Project Management: Cost, Time and Quality, Two Best Guesses and a Phenomenon, It's Time to Accept Other Success Criteria”, International Journal of Project Management, Vol. 17, No. 6, 1999, pp. 337-342.

4. Baker, B.N., D.C. Murphy, D. Fisher, "Factors Affecting Project Success, Project Management Handbook, 1988.

5. Cockburn, A., Agile Software Development, Addison Wesley, Boston, 2002.

6. $\quad$ Conner, D.R., Managing at the Speed of Change, Villard Books, New York, 1992.

7. Cooke-Davies, T., "The 'Real' Success Factors on Projects", International Journal of Project Management, Vol. 20, 2002, pp. 185-190.

8. De Wit, A. "Measurement of Project Success", International Journal of Project Management, Vol. 6, No. 3, August 1988, pp. 164-170.

9. Ewusi-Mensah K., Software Development Failures: Anatomy of Abandoned Projects, The MIT Press, Cambridge, MA, 2003.

10. Glass R.L., Computing Calamities: Lessons Learned from Products, Projects, and Companies that Failed, Prentice Hall, Upper Saddle River, NJ, 1999.

11. Jenkins, A.M., J.D. Naumann, J.C. Wetherbe, "Empirical Investigation of System Development Practices and Results", Information \& Management, Vol. 7, 1984, pp. 73-82.

12. Jorgensen, M., K. Molokken, "How Large Are Software Cost Overrruns? A Review of the 1994 CHAOS Report", Information and Software Technology, Vol. 48, No. 4, Apr. 2006.

13. Kolltveit, B.J., J.T. Karlsen, K Gronhaug, "Perspective on Project Management, International Journal of Project Management, Vol. 25, 1997, pp. 3-9.

14. Lipovetsky, S., A. Tishler, D. Dvir, A. Shenhar, "The Relative Importance of Project Success Dimensions", $R \& D$ Management, Vol. 27, No. 2, 1997, pp. 97-106. 
15. Lucas, Jr. H.C., Why Information Systems Fail, Columbia University Press, New York, 1975.

16. Male, S., J. Kelly, M Gronqvist, D. Graham, "Managing Value as a Management Style for Projects", International Journal of Project Management, Vol. 25, 1997, pp. 107-114.

17. Murphy T., Achieving Business Value from Technology: A Practical Guide for Today's Executive, John Wiley \& Sons, 2002.

18. Nauer, P., B. Randell, "Software Engineering: Report on a conference sponsored by the NATO Science Committee", Conference held in Garmisch, Germany, Oct 7-11, 1968.

19. Nicholas, J., H. Steyn, Project Management for Business, Engineering, and Technology, $3^{\text {rd }}$ edition, Butterworth-Heinemann, Burlington, MA, 2008.

20. O’Connor, M.M., L.H. Reinborough, “Quality Projects in the 1990's: A Review of Past Projects and Future Trends", International Journal of Project Management, Vol. 10, No.2, may 1992, pp. 107-114.

21. Office of Government Commerce, Managing Successful Projects with PRINCE2, The Stationary Office, Norwich, UK, 2005.

22. Paulish, D.J., Architecture-Centric Software Project Management, Addison-Wesley, Upper Saddle River, NJ, 2002.

23. Petter, S., D. Straub, A. Rai, "Specifying Formative Constructs in Information Systems Research", MIS Quarterly, Vol. 31, No. 4, December 2007, pp. 623-656.

24. Phan, D., D. Vogel, J. Nunamaker, "The Search for Perfect Project Management", Computerworld, September 26, 1988, pp. 95-100.

25. Phillips J.J., T.W. Bothell, G.L. Snead, The Project Management Scorecard: Measuring the Success of Project Management Solutions, Butterworth Heinemann, 2002.

26. Pinto, J.K., D.P. Slevin, "Project Success: Definitions and Measurement Techniques", Project Management Journal, Vol. 19, No. 1, 1988a, pp. 67-72.

27. Pinto, J.K., D.P. Slevin, "Critical Success Factors across the Project Life Cycle", Project Management Journal, Vol. 19, No. 3, 1988b, pp. 67-75.

28. Project Management Institute, A Guide to the Project Management Body of Knowledge (PMBOK $®$ Guide), Fourth Edition, Project Management Institute, 2008.

29. Randell, B., "Software Engineering in 1968", in Proceedings of the $4^{\text {th }}$ International Conference on Software Engineering, IEEE Press, Piscataway, NJ, 1979, pp. 1-10.

30. Sauer, C., A. Gemino, and B. Reich, "The Impact of Size and Volatility on IT Project Performance", Communications of the ACM, Vol. 50, No. 11, November 2007, pp. 79-84.

31. Shenhar, A.J., D. Dvir, Reinventing Project Management, Harvard Business School Press, Boston, MA, 2007.

32. The Standish Group, "Chaos", 2006. Available via www.standishgroup.com

33. Sutherland, J., "Agile Development: Lessons Learned from the First Scrum”, Cutter Agile Project Management Advisory Service: Executive Update, Vol. 5, 2004, pp. 1-4.

34. Tedesco, P., Common Sense in Project Management, Thomson Course Technology, Boston, MA, 2006.

35. Tiwana, A., M. Keil, “The One-Minute Risk Assessment Tool”, Communications of the ACM, Vol. 47, No. 11, Nov. 2004, pp. 73-77.

36. Ward J., Daniel E., Benefits Management: Delivering Value from IS \& IT Investments, John Wiley \& Sons, 2006

37. Weisbord M., Janoff S., Future Search: An Action Guide to Finding Common Ground in Organizations \& Communities, Berret-Koehler, San Francisco, 2000.

38. Yourdon E., Death March, $2^{\text {nd }}$ Ed., Prentice Hall, Upper Saddle River, NJ, 2004. 